\title{
Cardiovascular Disease Risk Associated to Chronic Inflammatory Rheumatic Diseases in Patients Seen in Rheumatology Unit in Yaounde, Cameroon
}

\author{
Madeleine Singwe-Ngandeu $u^{1,2 *}$, Mickael Essouma ${ }^{1}$, Alain Patrick Menanga ${ }^{1,3}$, \\ Vicky Jocelyne Ama Moor ${ }^{1,4}$, Caroline Ngoufack ${ }^{2}$, Sandrine Sa'a Lontsi'2, \\ Yolande Vanessa Ayi Efoua2, Thierry Ntandzi ${ }^{2}$ \\ ${ }^{1}$ Faculty of Medicine and Biomedical Sciences, University of Yaounde I, Yaounde, Cameroon \\ ${ }^{2}$ Rheumatology Unit, Yaounde Central Hospital, Yaounde, Cameroon \\ ${ }^{3}$ Cardiology Unit, Yaounde General Hospital, Yaounde, Cameroon \\ ${ }^{4}$ Biochemistry Laboratory, Yaounde University Teaching Hospital, Yaounde, Cameroun \\ Email: "ngandeum@yahoo.fr
}

Received 7 January 2016; accepted 16 February 2016; published 19 February 2016

Copyright (C) 2016 by authors and Scientific Research Publishing Inc.

This work is licensed under the Creative Commons Attribution International License (CC BY). http://creativecommons.org/licenses/by/4.0/

(c) (i) Open Access

\section{Abstract}

Introduction: Even though there is a huge burden of both chronic inflammatory rheumatic diseases (CIRD) and cardiovascular diseases in Sub-Saharan Africa, no published study from this region has yet addressed the issue of cardiovascular diseases in a group including different CIRD to the best of our knowledge. Objective: We conducted this research with the aim to explore the association between CIRD and cardiovascular risk in a Cameroonian population based on the World Health Organization (WHO) and International Society for Hypertension (ISH) risk charts. Methods: This cross-sectional study included CIRD patients, followed at the rheumatology unit of the Yaounde Central Hospital, and, who were matched to non-CIRD subjects for sex, age and race. Cardiovascular risk factors were studied and subsequently the cardiovascular risk was estimated using the WHO/ISH risk charts. Analyses were performed in Epi-info and SPSS software and results were considered statistically significant for a p-value less than 0.05 . Results: In total, 109 CIRD patients and 111 non-CIRD subjects were included. Their respective mean ages were 44.4 \pm 15.2 years and $44.2 \pm 15.1$ years. Odds ratio $2.09,95 \%$ confidence interval $(\mathrm{CI})(1.07-4.08)$; high BMI OR 1.89, 95\% CI (1.1 - 3.24); diabetes mellitus $(p=0.03)$ and physical inactivity $(p<0.001)$ were all markedly found in CIRD patients compared with controls. Ten (9.2\%) CIRD patients had a past history of atherosclerotic cardiovascular events compared with no control $(p<0.001)$. The cardiovascular

\footnotetext{
*Corresponding author.

How to cite this paper: Singwe-Ngandeu, M., Essouma, M., Menanga, A.P., Moor, V.J.A., Ngoufack, C., Lontsi, S.S., Efoua, Y.V.A. and Ntandzi, T. (2016) Cardiovascular Disease Risk Associated to Chronic Inflammatory Rheumatic Diseases in Patients Seen in Rheumatology Unit in Yaounde, Cameroon. Open Journal of Rheumatology and Autoimmune Diseases, 6, 13-21. http://dx.doi.org/10.4236/ojra.2016.61003
} 
risk estimated with the WHO/ISH risk charts was low in $43(79.6 \%)$ patients with CIRD versus 52 (88.1\%) non-CIRD subjects. Conclusions: CIRD were associated with hypertension, excess overall adiposity, diabetes mellitus, and physical inactivity. A substantially increased proportion of CIRD patients with a past history of atherosclerotic cardiovascular events were noted. But the WHO/ISH risk charts broadly found a similar and globally decremented cardiovascular risk in both study groups, highlighting the need to pursue research for definite conclusions on their reliability.

\section{Keywords} Chronic Inflammatory Rheumatic Diseases, Cardiovascular Risk, Cardiovascular Risk Factors,
Cardiovascular Disease, WHO/ISH Risk Charts, Sub-Saharan Africa

\section{Introduction}

Chronic inflammatory rheumatic diseases (CIRD) are a heterogeneous group of disorders characterized by humoral or cell-mediated immune responses against diverse autoantigens, with prominent involvement of synovial joints [1] [2]. CIRD morbidity is increasing in developing populations, and in particular in Sub-Saharan Africa where a prevalence of $8.2 \%$ has been reported in a Cameroonian hospital setting in 2007 [3] [4]. Genetic and environmental triggers commonly interact to determine the occurrence of CIRD [1].

It is widely known that CIRD i.e. rheumatoid arthritis (RA), ankylosing spondylitis (AS) and other spondyloarthritides (SpA), systemic lupus erythematosus (SLE), Sjögren's syndrome, systemic sclerosis, polymyalgia rheumatica, and vasculitides are frequently associated with comorbid conditions such as cardiovascular diseases (CVD) that significantly impact on patients' life span [1] [5] [6]. CIRD may increase the cardiovascular risk through several mechanisms including nontraditional cardiovascular risk factors alongside traditional cardiovascular risk factors. Nontraditional cardiovascular risk factors are essentially genetic/epigenetic mechanisms, disease-modifying antirheumatic drugs, and more specifically immune mechanisms together with chronic inflammation [1] [6].

Despite the increasing burden of both CIRD and CVD in Sub-Saharan Africa collectively with extensive assessment of their relationships in temperate regions [1] [3] [5]-[7], no published study has yet addressed the issue of CVD in a group of multiple CIRD in Black African patients to the best of our knowledge. The only reports investigating the link between CIRD and CVD in Sub-Saharan Africa focused on RA [8] [9]. Moreover, their results are discrepant. In this regard and considering the need for population specific stratification [8], the potential link between various CIRD and CVD might appear theoretical in Sub-Saharan Africa and thus deserve rigorous exploration in this region. Hence, we carried out a study aiming to investigate the association between CIRD and cardiovascular risk in a Cameroonian population based on the World Health Organization (WHO) and International Society for Hypertension (ISH) risk charts.

\section{Methodology}

CIRD patients enrolled in this cross-sectional study are members of a large cohort designed for all aspects of research in the domain of CIRD at the Yaounde Central Hospital rheumatology unit. The cohort comprises a large array of CIRD that were all included in this research: 1) RA diagnosed according to the American College of Rheumatology (ACR)/European League against Rheumatism (EULAR) criteria [10] [11], 2) systemic lupus erythematosus (SLE) and 3) systemic sclerosis both diagnosed with respect to their respective ACR criteria [12] [13], 4) mixed connective tissue disease fulfilled the Sharp criteria [14], 5) Sjögren's syndrome (SS) diagnosed as recommended by the American-European consensus group criteria [15], 6) autoimmune polymyositis fulfilled the Hoogendjick et al. criteria [16], 7) spondyloarthropathies diagnosed according to the Amor et al. criteria [17], 8) and adult onset Still's disease diagnosed according to the Fautrel et al. criteria [18]. Individuals of both sexes aged $\geq 18$ years all members of the cohort were recruited consecutively based on a non-probabilistic sampling and included in the CIRD group. Patients with human immunodeficiency virus infection, hereditary dyslipidemia, chronic kidney disease, and any other evolving chronic inflammatory disease were excluded from the study. 
Clinically healthy volunteers matched to patients for sex, age (timeframe of two years) and race were recruited from the Yaounde community and included in the non-CIRD group.

Pregnant women were excluded from both groups.

Demographic, clinical and biological data were recorded during a lone visit. Blood pressure was measured with a clinically validated electronic device (Magnien B1) [19]. Hypertension was defined by a systolic (and/or a diastolic) blood pressure $\geq 140$ (90) $\mathrm{mmHg}$ [20]. Body weight $(\mathrm{kg})$ was measured with a mechanical scale balance (precision $\pm 0.5 \mathrm{~kg}$ ) in participants barefoot and lightly dressed. Height $(\mathrm{m})$ was measured with a locally made stadiometer. Body Mass Index (BMI) was calculated using Quetelet's indices and excess adiposity was defined by a BMI $\geq 25 \mathrm{~kg} / \mathrm{m}^{2}$ [21]. Waist circumference was measured with a meter tape midway between the lower border of the twelfth rib and the antero-superior iliac spine and abdominal obesity was defined by a waist circumference $\geq 102 \mathrm{~cm}$ in men, and $\geq 88 \mathrm{~cm}$ in women [21]. Blood was drawn by venous puncture in the forearm crease after strict asepsis. The tubes were immediately sent to the biochemistry laboratory of the Yaounde University Teaching Hospital, and analyzed the same day for blood glucose, serum cholesterol, and uric acid.

Cardiovascular risk factors validated by the World Health Organization (WHO) [20]-[23] were investigated, and the cardiovascular risk was estimated from WHO/ISH risk charts appropriate for the Cameroonian general population [22]. With respect to these risk charts, each subject fits into one of the five risk categories: low $(<10 \%)$, moderate $(10 \%$ to $<20 \%)$, medium ( $20 \%$ to $<30 \%$ ), high ( $30 \%$ to $<40 \%)$, and very high $(\geq 40 \%)$ risk [22].

All analyses were performed in Epi-info for windows version 7, and SPSS for windows version 18. For continuous variables, the means and standard deviations were calculated. Categorical variables were expressed as frequencies with their $95 \%$ confidence intervals (CI).

The association between CVD/risk factors and CIRD was summarized with odds ratios (OR) and their 95\% CI. Multiple logistic regression (with methotrexate, corticosteroids, hydroxychloroquine, male sex, advanced age [ $\geq 55$ years in men, and $\geq 65$ years in women], and sedentarity as candidate predictors) was used to deeply question the relationship between CIRD specific factors and cardiovascular risk factors. A p-value $<0.05$ was considered statistically significant.

\section{Ethics Approval and Consent to Participate}

The research protocol was in accordance with the Declarations of Helsinki. An ethical clearance was obtained from the Institutional Ethics Committee of the Faculty of Medicine and Biomedical Sciences of the University of Yaounde I. Administrative authorizations to recruit and manipulate blood samples were obtained from the Yaounde Central and University Teaching Hospitals respectively. Each participant completed a written informed consent before enrolment.

This study protocol received the approval from the institutional ethical committee of Faculty of Medicine and Biomedical Sciences of the University of Yaounde I.

\section{Results}

Table 1 summarizes the demographic and clinical characteristics of participants. A total of 109 CIRD patients and 111 non-CIRD subjects were finally included. The CIRD group matched well with the non-CIRD group (mean age \pm SD $44.4 \pm 15.2$ years vs $44.2 \pm 15.5$ years for CIRD patients and non-CIRD participants respectively, $\mathrm{p}=0.82$ ).

For cardiovascular risk factors (Table 2), hypertension was recorded in $27.5 \%$ of the CIRD patients and $15.3 \%$ of the non-CIRD subjects "OR 2.09, 95\% CI (1.07 - 4.08), $\mathrm{p}=0.03$ ” excess overall adiposity reflected by high BMI was found in $63.3 \%$ of the CIRD subjects and $47.7 \%$ of the non-CIRD participants ["OR 1.89, 95\% CI (1.1 - 3.24), $\mathrm{p}=0.02$ " diabetes mellitus and physical inactivity were significantly noticed only in the CIRD group (7.3\%, $\mathrm{p}=0.003$ and $11 \%, \mathrm{p}<0.001$ for diabetes and physical inactivity respectively). The logistic regression showed that increasing age was independently associated with hypertension "adjusted OR 34.44, 95\% CI (6.46 185.79), $\mathrm{p}<0.001$ " whereas treatment with methotrexate was inversely associated with hypertension "adjusted OR 0.27, 95\% CI (0.07 - 0.95), p = 0.04" (Table 3). Furthermore, incremented BMI was independent of age (p $=0.1)$, gender $(\mathrm{p}=0.60)$, treatments with nonsteroidal antiinflammatory drugs $(\mathrm{p}=0.36)$, corticosteroids $(\mathrm{p}=$ $0.16)$, hydroxychloroquine $(\mathrm{p}=0.66)$, and methotrexate $(\mathrm{p}=0.75)$ (Table 4$)$.

Ten (9.2\%) CIRD patients had experienced atherosclerotic cardiovascular events before the study, thus were 
Table 1. Demographic and clinical characteristics of the study population.

\begin{tabular}{|c|c|c|c|}
\hline \multirow{2}{*}{ Characteristics } & \multicolumn{2}{|c|}{ CIRD } & \multirow{2}{*}{ p-value } \\
\hline & Present & Absent & \\
\hline Age (mean $\pm S D$ ), years & $44.4 \pm 15.2$ & $44.2 \pm 15.5$ & 0.82 \\
\hline \multicolumn{4}{|l|}{ Sex } \\
\hline -Females N (\%) & $39(78)$ & $39(76.5)$ & \multirow[t]{16}{*}{0.88} \\
\hline -Males N (\%) & $11(22)$ & $12(23.5)$ & \\
\hline Duration* (mean \pm SD), years & $9 \pm 7.6$ & N/A & \\
\hline CIRD, N (\%) & & N/A & \\
\hline -Rheumatoid arthritis & $50(45.9)$ & & \\
\hline -SLE & $21(19.3)$ & & \\
\hline -MCTD & $11(10.1)$ & & \\
\hline -Ankylosing spondylitis & $11(10.1)$ & & \\
\hline -Undifferentiated arthritis & $4(3.7)$ & & \\
\hline -Adult onset Still's disease & $4(3.7)$ & & \\
\hline -Systemic sclerosis & $2(1.8)$ & & \\
\hline -Goujerot-Sjögren’s syndrome & $2(1.8)$ & & \\
\hline -Reactive arthritis & $1(0.9)$ & & \\
\hline -Polymyositis & $1(0.9)$ & & \\
\hline -Crohn's disease & $1(0.9)$ & & \\
\hline -Psoriatic arthritis & $1(0.9)$ & & \\
\hline Comorbidities, N (\%) & $96(88)$ & N/A & \\
\hline -Infections & $73(67)$ & & \\
\hline -PUD & $56(51.4)$ & & \\
\hline -Osteoarthritis & $26(23.8)$ & & \\
\hline -Cancer & $3(2.7)$ & & \\
\hline -Asthma & $1(0.9)$ & & \\
\hline -Depression & $1(0.9)$ & & \\
\hline - Parkinson’s disease & $1(0.9)$ & & \\
\hline RA treatment, $\mathrm{N}(\%)$ & & NA & \\
\hline \multicolumn{4}{|l|}{-Symptomatic treatment } \\
\hline Prednisone & $53(48.6)$ & & \\
\hline NSAIDS & $12(11)$ & & \\
\hline \multicolumn{4}{|l|}{-Specific treatment } \\
\hline MTX & 38 (34.9) & & \\
\hline HCQ & $31(28.4)$ & & \\
\hline SSZ & $8(18.6)$ & & \\
\hline $\mathrm{AZT}$ & $7(10.1)$ & & \\
\hline LEF & $1(1.4)$ & & \\
\hline -Without treatment & $28(27.5)$ & & \\
\hline
\end{tabular}

CIRD: chronic inflammatory rheumatic diseases; SD: Standard Deviation; N: number; Duration*: duration of evolution of disease; NA: not applicable; RA: rheumatoid arthritis; SLE: systemic lupus erythematosus; MCTD: mixed connective tissue diseases; PUD: peptic ulcer disease; NSAIDs: nonsteroidal anti-inflammatory drugs; MTX: methotrexate; HCQ: hydroxychloroquine; AZT: azathioprine; SSZ: sulfasalazine; LEF: leflunomide. 
Table 2. Prevalence of cardiovascular risk factors in CIRD patients compared to non-CIRD participants.

\begin{tabular}{|c|c|c|c|c|c|c|c|}
\hline \multirow[t]{3}{*}{ Variables } & \multicolumn{4}{|c|}{ CIRD } & \multirow[t]{3}{*}{ OR } & \multirow[t]{3}{*}{$95 \%$ CI } & \multirow[t]{3}{*}{$\mathrm{p}$-value } \\
\hline & \multicolumn{2}{|c|}{ Present } & \multicolumn{2}{|c|}{ Absent } & & & \\
\hline & $\mathrm{N}$ & $\%$ & $\mathrm{~N}$ & $\%$ & & & \\
\hline Hypertension & 30 & 27.5 & 17 & 15.3 & 2.09 & $1.07-4.08$ & 0.03 \\
\hline $\mathrm{BMI} \geq 25 \mathrm{~kg} / \mathrm{m}^{2}$ & 69 & 63.3 & 53 & 47.7 & 1.89 & $1.1-3.24$ & 0.02 \\
\hline Abdominal obesity & 48 & 44 & 35 & 31.5 & 1.71 & $0.98-2.96$ & 0.08 \\
\hline Metabolic syndrome & 24 & 22 & 16 & 14.4 & 1.68 & $0.84-3.37$ & 0.16 \\
\hline Hyperuricemia & 12 & 11 & 8 & 7.2 & 1.59 & $0.62-4.06$ & 0.33 \\
\hline Dyslipidemia & 59 & 53.1 & 54 & 48.6 & 1.24 & $0.73-2.11$ & 0.42 \\
\hline Metabolic syndrome & 3 & 6 & 4 & 8 & 0.75 & $0.16-3.53$ & 1.00 \\
\hline Dyslipidemia & 25 & 50 & 30 & 59 & 0.7 & $0.32-1.54$ & 0.43 \\
\hline Menopause & 31 & 42.5 & 30 & 42.3 & 1.00 & $0.52-1.95$ & 0.98 \\
\hline Alcohol misuse & 9 & 8.3 & 27 & 24.3 & 0.28 & $0.12-0.63$ & 0.001 \\
\hline Tobacco use & 3 & 2.75 & 10 & 9 & 0.28 & $0.08-1.07$ & 0.08 \\
\hline Diabetes mellitus & 8 & 7.3 & - & - & $\mathrm{N} / \mathrm{C}$ & $\mathrm{N} / \mathrm{C}$ & 0.003 \\
\hline Physical in activity & 12 & 11 & - & - & $\mathrm{N} / \mathrm{C}$ & $\mathrm{N} / \mathrm{C}$ & $<0.001$ \\
\hline CVA/TIA* & 4 & 3.7 & - & - & $\mathrm{N} / \mathrm{C}$ & $\mathrm{N} / \mathrm{C}$ & 0.059 \\
\hline Ischemic heart disease" & 7 & 6.4 & - & - & $\mathrm{N} / \mathrm{C}$ & $\mathrm{N} / \mathrm{C}$ & 0.007 \\
\hline
\end{tabular}

CIRD: chronic inflammatory rheumatic diseases; OR: odds ratio; 95\% CI 95\%: confidence interval; N: number; BMI: body mass index; N/C: not calculable; CVA/TIA*: past history of cerebrovascular accident/transient ischemic attack; Ischemic heart disease "': $^{\prime \prime}$ past history of ischemic heart disease.

Table 3. Predictive factors for hypertension in CIRD subjects.

\begin{tabular}{ccccccccccc}
\hline & \multicolumn{3}{c}{ Unadjusted OR } & \multicolumn{3}{c}{ Adjusted OR } \\
& OR & CI** Min & CI Max & $\mathrm{p}^{*}$ & & OR & CI** Min & CI Max & $\mathrm{p}^{*}$ \\
\hline MTX & 0.59 & 0.23 & 1.50 & 0.27 & MTX & 0.27 & 0.07 & 0.95 & 0.04 \\
HCQ & 0.89 & 0.34 & 2.27 & 0.80 & HCQ & 0.86 & 0.26 & 2.90 & 0.81 \\
Prednisone & 1.89 & 0,80 & 4.43 & 0.15 & Prednisone & 1.86 & 0.62 & 5.62 & 0.27 \\
NSAIDS & 0.86 & 0.22 & 3.44 & 0.84 & NSAIDS & 1.95 & 0.33 & 11.63 & 0.46 \\
Age & 19.37 & 4.97 & 75.54 & $<0.001$ & Age & 34.44 & 6.46 & 185.79 & $<0.001$ \\
Male gender & 0.98 & 0.39 & 2.46 & 0.97 & Male gender & 0.35 & 0.09 & 1.42 & 0.14 \\
\hline
\end{tabular}

OR: odds ratio; CI**: Min confidence interval minimum; CI: Max confidence interval maximum; $\mathrm{p}^{*}$ : p-value; MTX: methotrexate; HCQ: hydroxychloroquine; NSAIDS: nonsteroidal antiinflammatory drugs.

Table 4. Putative predictive factors for high BMI in CIRD patients.

\begin{tabular}{ccccccccccc}
\hline & \multicolumn{3}{c}{ Unadjusted OR } & \multicolumn{4}{c}{ Adjusted OR } \\
& OR & CI** Min & CI Max & p* & & OR & CI Min & CI Max & $\mathrm{p}^{*}$ \\
\hline MTX & 1.18 & 0.52 & 2.69 & 0.69 & MTX & 1.16 & 0.47 & 2.82 & 0.75 \\
HCQ & 0.73 & 0.31 & 1.72 & 0.47 & HCQ & 0.81 & 0.31 & 2.12 & 0.66 \\
Prednisone & 0.67 & 0.31 & 1.46 & 0.31 & Prednisone & 0.54 & 0.23 & 1.28 & 0.16 \\
NSAIDs & 0.54 & 0.16 & 1.80 & 0.32 & NSAIDs & 0.54 & 0.14 & 2.05 & 0.36 \\
Age & 2.86 & 0.76 & 10.74 & 0.12 & Age & 3.26 & 0.81 & 13.05 & 0.1 \\
Male gender & 0.85 & 0.37 & 1.97 & 0.7 & Male gender & 0.76 & 0.28 & 2.10 & 0.60 \\
\hline
\end{tabular}

OR: odds ratio; CI**: Min confidence interval minimum; CI: Max confidence interval maximum; p*: p-value; MTX: methotrexate; HCQ: hydroxychloroquine; NSAIDS: nonsteroidal antiinflammatory drugs. 
considered "at very high risk individuals", and no participant from the non-CIRD group had ever experienced such events ( $p<0.001$ for this comparison). Based on gender, age, diabetic/non diabetic status, tobacco smoking status, systolic blood pressure and blood cholesterol values in absence of previous atherosclerotic cardiovascular events [22], the cardiovascular risk could be estimated with WHO/ISH risk charts only in 54 CIRD patients versus 59 non-CIRD subjects (Figure 1). According to this estimation, the cardiovascular risk was low in 43 (79.6\%) CIRD patients vs $52(88.1 \%)$ non-CIRD participants ( $\mathrm{p}=0.53)$, moderate in six $(11.1 \%)$ CIRD patients vs three $(5.1 \%)$ non-CIRD participants $(\mathrm{p}=0.31)$, medium in three $(5.6 \%)$ CIRD patients vs one $(1.7 \%)$ nonCIRD subject (0.35), high in one (1.8\%) CIRD patient vs two (3.4\%) non-CIRD subjects ( $\mathrm{p}=1.00)$, and very high in one $(1.8 \%)$ CIRD patient and one (1.7\%) non-CIRD participant ( $\mathrm{p}=1.00)$. In summary, the number of CIRD people with previous cardiovascular events was significantly incremented in comparison with the nonCIRD group. But when the cardiovascular risk was estimated with the WHO/ISH risk charts, there was no association between the cardiovascular risk and CIRD.

\section{Discussion}

We studied both the cardiovascular risk factors and the CVD risk in a Black African cohort of patients with CIRD from an urban Cameroonian setting, with aim to explore the relationship between multiple CIRD and CVD risk. Resultantly, CIRD were associated with hypertension, excess overall adiposity, diabetes mellitus and physical inactivity. A Dutch study including 3356 CIRD patients and 6708 matched controls similarly reported a significantly higher prevalence of hypertension in the group of CIRD patients compared with controls ( $12 \%$ vs 9\%, "Hazard ratio 1.3, 95\% CI (1.1 - 1.5), p = 0.001" [24]. Furthermore, excess adiposity has also been previously reported in Black African RA patients and could be a risk factor for arthritis development and progression [8] [25]. Like in the general population [26], excess adiposity and most importantly increased age might substantially favor the development of hypertension in the context of CIRD. Notably, increased age was over 34 times independently associated with hypertension in CIRD patients. But astonishingly, treatment with methotrexate reduced by $73 \%$ the risk of developing hypertension in CIRD patients. This sheds light on a potential new role of methotrexate as an effective antihypertensive drug in the CIRD population alongside angiotensin receptor blockers. Along this line, it is possible that methotrexate-an anti-inflammatory drug-decrement blood pressure level in CIRD patients by inhibiting the renin-angiotensin system which is suggested to play an important

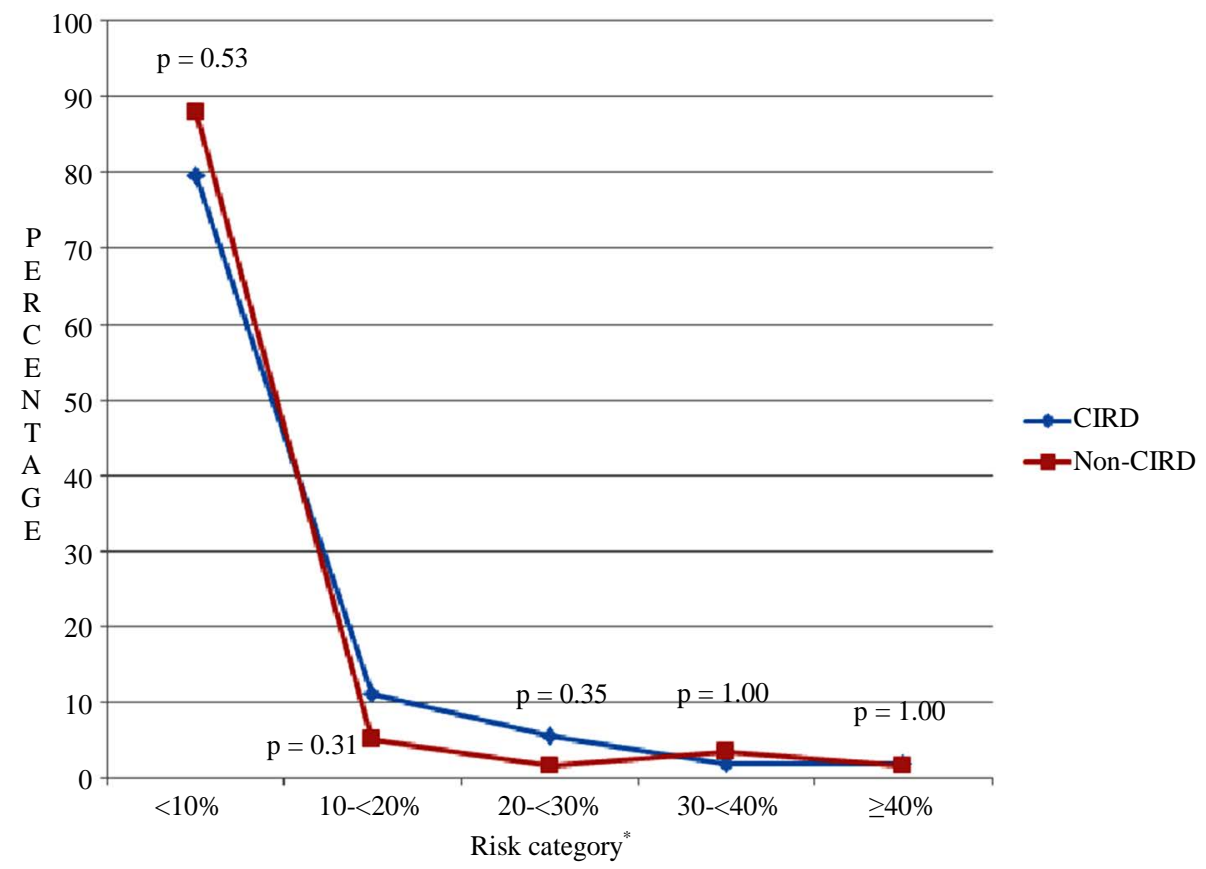

*The risk category has been estimated for 54 CIRD and 59 non-CIRD subjects

Figure 1. Cardiovascular risk of CIRD patients compared to non-CIRD subjects. 
role in the development of endothelial dysfunction and hypertension in CIRD through induction and worsening of vascular oxidative stress and inflammation [27] [28]. On the other hand, the association between CIRD and diabetes found here is supported by a meta-analysis of Wang et al., who found inflammatory markers including interleukin 6 (IL-6) and C-reactive protein (CRP) as risk factors for type 2 diabetes mellitus [29]. Indeed, CRP synthesis is driven by IL-6 and IL-6 may contribute to the pathophysiology of type 2 diabetes mellitus through its interaction with insulin-signaling pathways and $\beta$-cell function [29] [30]. Physical inactivity significantly prevalent in these CIRD patients has been described elsewhere in RA patients. The long diagnosis delay when patients already experience invalidating joint pain might be an explanation to this finding.

Recent insights have clearly demonstrated that CIRD patients have an incremented CVD risk [5] [6] [31]. The results of our study further support this knowledge. In fact, a significant proportion of CIRD patients had already experienced atherosclerotic cardiovascular diseases i.e. cerebrovascular accidents/transient ischemic attacks and/or ischemic heart disease, thus had a very high CVD risk. However, when estimating the cardiovascular risk with the WHO/ISH risk charts, CIRD patients did not significantly differ from their non-CIRD counterparts, and similarly had a broadly reduced cardiovascular risk. Remarkably, many cardiovascular risk calculators appropriate for the general population have been tested in RA patients [8] [27] [32] [33], but not in the other CIRD populations. Almost all of those studies have reported a low CVD risk and substantial underestimation of the CVD risk when using those calculators. Our results seem consistent with those reports in a CIRD population at large. However, we found CIRD associated with traditional CVD risk factors, contrasting with the estimated global low cardiovascular risk. Furthermore, CIRD patients frequently have an increased carotid intima-media thickness and high carotid plaque prevalences correctly suggestive of increased atherosclerosis burden [31]. Taken together, the WHO/ISH risk charts could have underestimated the CVD risk in our CIRD population. Hence, measurements of the aforementioned surrogate markers of atherosclerosis (carotid-intima media thickness and carotid plaque) as well as longitudinal studies are largely warranted for definite conclusions. In particular, crosssectional studies confronting the WHO/ISH risk charts estimations with concomitant measures of surrogate markers of atherosclerosis and longitudinal studies verifying if CVD outcomes/status predicted by the WHO/ ISH risk charts occur in the future would be helpful.

Our study had limitations:

- Caution must be exercised when interpreting results of this study. Indeed, causality of the observed associations cannot be guaranteed.

- Additionally, we cannot rule out the recall bias concerning the report of individual's previous cardiovascular events in spite of the use of adapted questionnaires developed by the WHO [21].

- Nevertheless, we studied the cardiovascular risk in an extensive CIRD population.

\section{Conclusion}

We found CIRD associated with hypertension, excess overall adiposity, diabetes mellitus and physical inactivity. In addition, a considerable proportion of CIRD patients reported previous atherosclerotic cardiovascular events. However, CIRD may not be associated with an increased CVD risk according to the WHO/ISH risk charts. Thus, definite conclusions require further rigorous research to precise if we can or not rely on the WHO/ISH risk charts to predict the CVD outcome in Black African patients with CIRD.

\section{Competing Interests}

The authors declare that they have no competing interests.

\section{Acknowledgements}

We thank the paramedical staff of the Rheumatology unit of the Yaounde Central Hospital who helped us for data collection and Mr. Djoufack Donald for his invaluable help in data analysis.

\section{References}

[1] López-Pedrera, C., Pérez-Sánchez, C., Ramos-Casals, M., Santos-Gonzalez, M., Rodriguez-Ariza, A. and Cuadrado, M.J. (2012) Cardiovascular Risk in Systemic Autoimmune Diseases: Epigenetic Mechanisms of Immune Regulatory Functions. Clinical and Developmental Immunology, 2012, Article ID: 974648. http://dx.doi.org/10.1155/2012/974648 
[2] Ralandison, S. (2012) Arthralgie Chronique: Comment Diagnostiquer un Rhumatisme Inflammatoire Chronique? Revue Médicale de Madagascar, 1, 79-89.

[3] Smith, E., Hoy, D.G., Cross, M., Vos, T., Naghavi, M., Buchbinder, R., et al. (2014) The Global Burden of Other Musculoskeletal Disorders: Estimates from the Global Burden of Disease 2010 Study. Annals of the Rheumatic Diseases, 73, 1462-1469. http://dx.doi.org/10.1136/annrheumdis-2013-204680

[4] Singwe-Ngandeu, M., Meli, J., Ntsiba, H., Nouédoui, C., Yollo, A.V., Sida, M.B., et al. (2007) Rheumatic Diseases in Patients Attending a Clinic at a Referral Hospital in Yaounde, Cameroon. East African Medical Journal, 84, 404-409.

[5] Zöller, B., Li, X., Sundquist, J. and Sundquist, K. (2012) Risk of Subsequent Ischemic and Hemorrhagic Stroke in Patients Hospitalized for Immune-Mediated Diseases: A Nationwide Follow-Up Study from Sweden. BMC Neurology, 12, 41. http://dx.doi.org/10.1186/1471-2377-12-41

[6] Zöller, B., Li, X., Sundquist, J. and Sundquist, K. (2012) Risk of Subsequent Coronary Heart Disease in Patients Hospitalized for Immune-Mediated Diseases: A Nationwide Follow-Up Study from Sweden. PloS One, 7, e33442. http://dx.doi.org/10.1371/journal.pone.0033442

[7] GBD 2013 Mortality and Causes of Death Collaborators (2015) Global, Regional, and National Age-Sex Specific All-Cause and Cause-Specific Mortality for 240 Causes of Death, 1990-2013: A Systematic Analysis for the Global Burden of Disease Study 2013. Lancet, 385, 117-171. http://dx.doi.org/10.1016/S0140-6736(14)61682-2

[8] Solomon, A., Tsang, L., Woodiwiss, A.J., Millen, A.M.E., Norton, G.R. and Dessein, P.H. (2014) Cardiovascular Disease Risk amongst African Black Patients with Rheumatoid Arthritis: The Need for Population Specific Stratification. BioMed Research International, 2014, Article ID: 826095. http://dx.doi.org/10.1155/2014/826095

[9] Kirui, F., Oyoo, G.O., Ogola, E.N. and Amayo, E.O. (2013) Cardiovascular Risk Factors in Patients with Rheumatoid Arthritis at Kenyatta National Hospital. African Journal of Rheumatology, 1, 15-22.

[10] Arnett, F.C., Edworthy, S.M., Bloch, D.A., McShane, D.J., Fries, J.F., Cooper, N.S., et al. (1988) The American Rheumatism Association 1987 Revised Criteria for the Classification of Rheumatoid Arthritis. Arthritis \& Rheumatology, 31, 315-324. http://dx.doi.org/10.1002/art.1780310302

[11] Aletaha, D., Neogi, T., Silman, A.J., Funovits, J., Felson, D.T., Bingham III, C.O., et al. (2010) 2010 Rheumatoid Arthritis Classification Criteria: An American College of Rheumatology/European League against Rheumatism Collaborative Initiative. Arthritis \& Rheumatism, 62, 2569-2581. http://dx.doi.org/10.1002/art.27584

[12] Tan, E.M., Cohen, A.S., Fries, J.F., Masi, A.T., McShane, D.J., Rothfield, N.F., et al. (1982) The 1982 Revised Criteria for the Classification of Systemic Lupus Erythematosus. Arthritis \& Rheumatism, 25, 1271-1277. http://dx.doi.org/10.1002/art.1780251101

[13] Avouac, J., Kahan, A. and Allanore, Y. (2010) Sclérodermie systémique: Critères diagnostiques et de suivi. Revue du Rhumatisme Monographies, 77, 103-107. http://dx.doi.org/10.1016/j.monrhu.2010.01.010

[14] Ortega-Hernandez, O.-D. and Shoenfeld, Y. (2012) Mixed Connective Tissue Disease: An Overview of Clinical Manifestations, Diagnosis and Treatment. Best Practice \& Research Clinical Rheumatology, 26, 61-72. http://dx.doi.org/10.1016/j.berh.2012.01.009

[15] Rasmussen, A., Ice, J.A., Li, H., Grundahl, K., Kelly, J.A., Radfar, L., et al. (2014) Comparison of the American-European Consensus Group Sjogren’s Syndrome Classification Criteria to Newly Proposed American College of Rheumatology Criteria in a Large, Carefully Characterised Sicca Cohort. Annals of the Rheumatic Diseases, 73, 31-38. http://dx.doi.org/10.1136/annrheumdis-2013-203845

[16] Hoogendijk, J.E., Amato, A.A., Lecky, B.R., Choy, E.H., Lundberg, I.E., Rose, M.R., et al. (2004) 119th ENMC International Workshop: Trial Design in Adult Idiopathic Inflammatory Myopathies, with the Exception of Inclusion Body Myositis, 10-12 October 2003, Naarden, The Netherlands. Neuromuscular Disorders, 14, 337-345. http://dx.doi.org/10.1016/j.nmd.2004.02.006

[17] Wendling, D., Prati, C., Toussirot, É. and Ornetti, P. (2010) Spondylarthrite, spondylarthropathies: Critères de diagnostic et de classification. Revue du Rhumatisme Monographies, 77, $43-47$. http://dx.doi.org/10.1016/j.monrhu.2009.12.002

[18] Fong, W.S. and Lui, N.L. (2013) Adult Onset Still’s Disease: A Review. Proceedings of Singapore Healthcare, 22, 40-47. http://dx.doi.org/10.1177/201010581302200107

[19] Tensiomètre Médical Brassard B1 Magnien (2014). http://medical.fr/fr/33281-tensiometre-medical-brassard.html

[20] Whitworth, J.A., World Health Organization, International Society of Hypertension Writing Group (2003) 2003 World Health Organization (WHO)/International Society of Hypertension (ISH) Statement on Management of Hypertension. Journal of Hypertension, 21, 1983-1992. http://dx.doi.org/10.1097/00004872-200311000-00002

[21] WHO (2014) OMS. Comment éviter une crise cardiaque ou un accident vasculaire cérébral. http://www.who.int/publications/list/9241546727/fr/ 
[22] OMS. Prévention des maladies cardiovasculaires. WHO. cited April 2014. http://www.who.int/publications/list/cadio_pocket_guidelines/fr/

[23] Alberti, K.G. and Zimmet, P.Z. (1998) Definition, Diagnosis and Classification of Diabetes Mellitus and Its Complications. Part 1: Diagnosis and Classification of Diabetes Mellitus Provisional Report of a WHO Consultation. Diabetic Medicine, 15, 539-553. http://dx.doi.org/10.1002/(SICI)1096-9136(199807)15:7<539::AID-DIA668>3.0.CO;2-S

[24] Ursum, J., Nielen, M.M., Twisk, J.W., Peters, M.J., Schellevis, F.G., Nurmohamed, M.T., et al. (2013) Increased Risk for Chronic Comorbid Disorders in Patients with Inflammatory Arthritis: A Population Based Study. BMC Family Practice, 14, 199. http://dx.doi.org/10.1186/1471-2296-14-199

[25] Gremese, E., Carletto, A., Padovan, M., Atzeni, F., Raffeiner, B., Giardina, A., et al. (2013) Obesity and Reduction of the Response Rate to Anti-Tumour Necrosis Factor Alpha in Rheumatoid Arthritis: An Approach to a Personalized Medicine. Arthritis Care \& Research, 65, 94-100. http://dx.doi.org/10.1002/acr.21768

[26] Perk, J., De Backer, G., Gohlke, H., Graham, I., Reiner, Z., et al. (2012) European Guidelines on Cardiovascular Disease Prevention in Clinical Practice (Version 2012): The Fifth Joint Task Force of the European Society of Cardiology and Other Societies on Cardiovascular Disease Prevention in Clinical Practice (Constituted by Representatives of Nine Societies and by Invited Experts) * Developed with the Special Contribution of the European Association for Cardiovascular Prevention \& Rehabilitation (EACPR). European Heart Journal, 33, 1635-1701. http://dx.doi.org/10.1093/eurheartj/ehs092

[27] Peters, M.J.L., Symmons, D.P.M., McCarey, D., Dijkmans, B.A.C., Nicola, P., Kvien, T.K., et al. (2010) EULAR Evidence-Based Recommendations for Cardiovascular Risk Management in Patients with Rheumatoid Arthritis and Other Forms of Inflammatory Arthritis. Annals of the Rheumatic Diseases, 69, 325-331. http://dx.doi.org/10.1136/ard.2009.113696

[28] Panoulas, V.F., Metsios, G.S., Pace, A.V., John, H., Treharne, G.J., Banks, M.J., et al. (2008) Hypertension in Rheumatoid Arthritis. Rheumatology, 47, 1286-1298. http://dx.doi.org/10.1093/rheumatology/ken159

[29] Wang, X., Bao, W., Liu, J., OuYang, Y.-Y., Wang, D., Rong, S., et al. (2013) Inflammatory Markers and Risk of Type 2 Diabetes: A Systematic Review and Meta-Analysis. Diabetes Care, 36, 166-175. http://dx.doi.org/10.2337/dc12-0702

[30] Gabay, C. (2006) Interleukin-6 and Chronic Inflammation. Arthritis Research \& Therapy, 8, S3. http://dx.doi.org/10.1186/ar1917

[31] Tyrell, P., Beyene, J., Feldman, B., McCrindle, B., Silvermann, E. and Bradley, T. (2010) Rheumatic Disease and Carotid Intima-Media Thickness: A Systematic Review and Meta-Analysis. Arteriosclerosis, Thrombosis, and Vascular Biology, 30, 1014-1026. http://dx.doi.org/10.1161/ATVBAHA.109.198424

[32] Semb, A.G., Rollefstad, S., van Riel, P., Kitas, G.D., Matteson, E.L. and Gabriel, S.E. (2014) Cardiovascular Disease Assessment in Rheumatoid Arthritis: A Guide to Translating Knowledge of Cardiovascular Risk into Clinical Practice. Annals of the Rheumatic Diseases, 73, 1284-1288. http://dx.doi.org/10.1136/annrheumdis-2013-204792

[33] Soubrier, M., Barber Chamoux, N., Tatar, Z., Couderc, M., Dubost, J.-J. and Mathieu, S. (2014) Cardiovascular Risk in Rheumatoid Arthritis. Joint Bone Spine, 81, 298-302. http://dx.doi.org/10.1016/j.jbspin.2014.01.009 